\title{
Understanding a Pedestrian Needs: Cases of metropolitan area
}

\author{
Rohana Sham 1, Noranita Abdamia 2, \\ Dia Widyawati Amat 3, Nurul Huda Md Yatim4
}

\author{
${ }^{1}$ Faculty of Business Management, \\ UCSI University, Malaysia \\ 2Faculty of Business Management, \\ ${ }^{3}$ Academy of Language Study, \\ ${ }^{4}$ Faculty of Information Management, \\ Universiti Teknologi Mara Johor Campus, Malaysia
}

rohana@ucsiuniversity.edu.my, noran801@johor.uitm.edu.my, diawidyawati@gmail.com, HMYatim@gmail.com

\begin{abstract}
Understanding the pedestrian needs is crucial. Malaysian citizen, especially those living in the city centre, has been too dependent on private transports due to high dissatisfaction towards pedestrian design provision. This includes cleanliness, accessibility and connectivity. Main objective of the research is to determine the factors that affect pedestrian satisfaction and to propose a solution model. This research embarks into a quantitative study where daily and active pedestrian were interview using a stated preference survey in Kuala Lumpur urban area. The research suggests a details understanding of the pedestrian needs among urban citizen who live and work in the city.
\end{abstract}

Keywords: Pedestrian Need; Urban Area; Infrastructure; Satisfaction

eISSN 2398-4295 @2020 The Authors. Published for AMER ABRA cE-Bs by e-International Publishing House, Ltd., UK. This is an open access article under the CC BY-NC-ND license (http://creativecommons.org/licenses/bync-nd/4.0/). Peer-review under responsibility of AMER (Association of Malaysian Environment-Behaviour Researchers), ABRA (Association of Behavioural Researchers on Asians) and CE-Bs (Centre for EnvironmentBehaviour Studies), Faculty of Architecture, Planning \& Surveying, Universiti Teknologi MARA, Malaysia.8pt Italic DOI: http://dx.doi.org/10.21834/ajbes.v5i18.189 


\subsection{Introduction}

Walkability environment is one of the crucial elements in shaping the city existence on and around the street. Walking helps to connect society from all end to their final destination. Walking also assist the vulnerable users where it includes children, women and the elderly as equitable access are given through walking (Borst, 2009). According to the report done by WHO (2013), only 68 countries in the world had policies to enhance the walking and cycling environment for the residents, causing that a continuous declination of users on walking trips and increment on the usage of private vehicles. A good pedestrian network would also contribute to the attraction of tourists for tourism activities where visitors would be able to travel on walking (Zakaria and Ujang, 2015). Therefore, showing that the infrastructure of the pedestrian road is vital for people moving around the area.

This study aims to find out factors that affect pedestrian satisfaction and to propose a solution model to resolve the factors identified. The planners of roads would able to understand and get insights on the needs of pedestrian where improvements can be made through this study. The research would begin with the introduction of the study, followed by the review of previous researchers work; then a methodology is provided to carry out the analysis and analysis would be done through the method proposed. Lastly, the conclusion would be given for improvements.

\subsection{Literature Review}

Prior researchers had done several types of research on the pedestrian needs on the road where different areas and cities were studied. However, there is no significant study on the pedestrian needs in the context of the metropolitan area in Malaysia, hence the gap is identified.

The theory developed by Maslow (1954) indicated that human needs have to be fulfilled where it can be similar to apply to the pedestrian needs where the walking environment is essential. There would be a firm expectation from the pedestrians' perspectives when deciding on walking.

In the study of Mateo-Babiano (2015), the paper presented different attributes on residents selecting on pedestrian decision primary process. The characteristics include: protection, ease, equitable access, mobility, enjoyment and identity and the researcher also highlighted that the authority should adopt the approach of user-centred needs assessment to understand the pedestrian's decision and behaviour of walking in the area.

The study of Rankavat and Tiwari (2016) indicates that the use or non-use of pedestrians' facilities is more to a habit of not coincidental behaviour on the perceptions of safety and convenience.

The approach of encouraging people to walk would provide various benefits. The issues on social and environmental issues relating to traffic and transportation would be resolved, thus in the study of Bivina and Parida (2019), a safe pedestrian infrastructure needed to be provided by the authority for residents to feel safe and comfortable to walk on the road. In the same study, the researchers had identified that comfort and convenience is one of the 
factors of pedestrian choice of main criteria for walking where the researchers proposed to have policy interventions for enhancing the comfortability of sidewalk and walking path. A built environment would provide a significant impact on the pedestrian walking frequency, including facilities and weathers, thus affecting pedestrians" perceptions on willingness to walk (Ariffin\&Zahari, 2013).

Different barriers arose which would discourage pedestrian use on walking where it might be safe and opportunities issues. In the study of Shafabakhsh et al. (2015), the use of the Analytical Hierarchical Process (AHP) in Multi-Criteria Decision Analysis (MCDA) approach would be suitable to determine different aspects on the building. A better pedestrian environment where it includes: identify the best pedestrian zones and mental satisfaction with physical characteristics of sidewalks.

By having a proper pedestrian development, a sustainable environment can be achieved, and a safe and appealing pedestrian network would contribute to higher usage of the pedestrian can be obtained to secure a sustainable future, providing a better environment for future generation (Alam\&Tasneem, 2018).

In the study of Atuah et al. (2017), the safety on the accessibility of crosswalk was a challenge to residents in urban, especially the disabled, children and pregnant women. The problems arise from factors such as inappropriate crossing points and place of walking. Installation of safety appurtenances would increase the safety and comfortability of the pedestrians.

Sham et al. (2013), stated that to ensure the safety of female away from crime, there is a need to ensure the proper planning on transport infrastructure. It includes the walking area to the public transport, which would consist of the use of the pedestrian walkway, showing that the pedestrian walkway would have a significant impact on the ease of access to public transportation. Furthermore, a high level of functional and comfortable walking space would be able to contribute to a safe and high-quality urban life where accessibility to different areas of the city would be more accessible through walking. A good infrastructure on pedestrian walkway would contribute towards a walkable urban structure. It will reduce the dependability in automobiles, and it would be beneficial to the ageing society where the elders would not be able to drive and would require walking to fulfil needs, such as country like Japan (Nakatsukasa\& Suzuki, 2017). However, in the same research, the researchers highlighted that if the pedestrians feel comfort in walking, there would be a risk for the pedestrian as the pedestrian would not be the focus and attentive to the surrounding environment, causing threats to pedestrians of their safety. In the context of Indonesia, pedestrians are willing to travel to the bus station if the pedestrian walkway is comfortable by having shady trees and canopy, showing that the comfortability is an essential aspect on residents travelling (Tjahjono et al., 2017). Adequacy of path wide is also one of the elements would be attracting pedestrians to use the trail where it shall be designed by comparing the pedestrian flows of the areas.

Pedestrians can be identified as the most vulnerable users on the urban streets; therefore, care shall be given to the pedestrian by having a better design to improve on 
safety on different road facilities, including intersections and road crossing (Asadi-Shekari et al., 2015).

In ensuring the facilities of the current urban streets, a Pedestrian Safety Index (PSI) can be used to measure the pedestrian's safety (Asadi-Shekari et al., 2015). According to a study done by Rupasinghe (2018) in the case of the city of Kandy, the comfort of the pedestrian can be achieved through the implementation on the street greenery where the at the same time carbon dioxide concentration can be reduced and sustainability of the city can be reached as well.

\subsection{Methodology}

The study proceeds with aquantitative method. Data are collected through a set of questionnaires designed. The respondent was selected among the active pedestrian user who is living and working in Kuala Lumpur metropolitan area. To achieve a maximum amount of data accuracy, a confirmation of the respondent nationality would be done at the initial stage to qualify them as respondents for the study. Besides that, internal consistency check through Cronbach alpha was carried out (Malhotra,2006).

\subsection{Results}

This section discusses the descriptive analysis of the demographic background and the satisfaction level towards the current pedestrian attributes

\subsection{Descriptive Analysis}

The first part of the finding discussed the demographic analysis of the respondents. This section explains on the sample profile of the current pedestrian users. Summary of their responses in the questionnaire will be clarified in the form of a table and pie chart. The first set of analysis examined the demographic characteristics of the pedestrian users for this study. The results are depicted in Table 1.

Table 1 Respondents 'Gender

\begin{tabular}{ccc}
\hline Gender & Frequency & $\begin{array}{c}\text { Percentage } \\
(\%)\end{array}$ \\
\hline Male & 183 & 47.8 \\
Female & 201 & 52.2 \\
Total & 384 & 100.0 \\
\hline
\end{tabular}

The distribution of the demographic pattern data among the pedestrian usage in the Kuala Lumpur city. The majority of pedestrian users who depended on the high usage of pedestrian facilities consisted of a female with $52.2 \%$ (201 respondents) and followed by male with $47.8 \%$ (184). 
Apart from the respondent's gender, the demographic analysis also focuses on the age of the respondents. The results are depicted in Table 2.

Table 2: Respondents Age

\begin{tabular}{ccc}
\hline Age & Frequency & Percentage (\%) \\
\hline Less than 18 & 2 & 5 \\
$18-27$ & 254 & 66.2 \\
$28-37$ & 74 & 19.2 \\
$38-47$ & 38 & 10.1 \\
$48-57$ & 15 & 3.9 \\
Total & 384 & 100.0 \\
\hline
\end{tabular}

It is apparent from Table 2 that only two respondents were reported from the age of less than $18(5 \%)$, a total of $254(66.2 \%)$ out of 384 respondents were reported from age 18-27 years old. Around 74 respondents (19.2\%) are from the age around 28- 37. The result indicates the active group of walking and utilizing the pedestrian walkways were among the young people who do not own any transport. Table 3 further tap on their income level.

Table 3: Respondents Income

\begin{tabular}{ccc}
\hline Income & Frequency & Percentage (\%) \\
\hline Less than RM1000 & 135 & 35.1 \\
RM1001-RM2500 & 46 & 11.9 \\
RM1501-RM4000 & 130 & 33.8 \\
RM4001-RM5500 & 42 & 10.9 \\
More RM5500 & 31 & 8.3 \\
Total & 384 & 100.0 \\
\hline
\end{tabular}

From Table 3, the majority of the pedestrian in Kuala Lumpur consisted of those with an income level of less than RM1000. This makes a total of $35.1 \%$ out of the total respondents (384 respondents). This result shows that majority of the current pedestrians were lowincome earners who depended on walking to commute to the place they want (workplace). Capturing their level of satisfaction is crucial because given a choice in the future, these pedestrians would shift from using pedestrian's walkway to transportation if they perceived that the current pedestrian's walkway environment was not satisfying to them.

Despite the employment category, the research also analyzes the frequency of pedestrian walkways usage per week. The results are shown in Table 4.

Table 4: Frequency of pedestrian walkway usage per week.

\begin{tabular}{ccc}
\hline Usage & $\begin{array}{c}\text { Freque } \\
\text { ncy }\end{array}$ & Percentage (\%) \\
\hline Less than one day & 63 & 16.4 \\
Two days & 24 & 6.2 \\
Three days & 37 & 9.6 \\
Four days & 48 & 12.5 \\
Five days & 58 & 15.1
\end{tabular}




$\begin{array}{ccc}\text { Six days } & 46 & 11.9 \\ \text { Seven days } & 108 & 28.3 \\ \text { Total } & 384 & 100.0\end{array}$

Table 4 shows that the majority of the pedestrians used pedestrian walkways for more than seven days(28.3\%). The least is for the usage of 2 days $(6.2 \%)$.

In the current study, the comparison of the level income earned, and pedestrian's walkway usage shows that the majority of an urban user in Kuala Lumpur city centre consisted of those from a medium-income group who travel to their final destination with a frequency walking of 7 days per week.

\subsection{Measuring Pedestrian Satisfaction Level}

The following section discussed on the satisfaction level towards the pedestrian design attributes being provided to them while walking into the city centre.

Table 5: Satisfaction level of pedestrian usage towards the comfortability of walkway

\begin{tabular}{lcc} 
I am comfortable walking on the pedestrian & & \\
walkway & Frequency & Percentage \\
\hline Strongly disagree & 22 & 5.7 \\
Disagree & 57 & 14.8 \\
Somewhat disagree & 153 & 39.7 \\
Agree & 101 & 26.2 \\
Strongly agree & 51 & 13.5 \\
Total & 384 & 100.0 \\
\hline
\end{tabular}

From Table 5 above, most of the pedestrians choose somewhat disagree with this question which consists of $39.7 \%$. And the second most chosen scale which is agreed has $101(26.2)$ respondents. And there are $22(5.7 \%)$ of respondents strongly disagree with the statement.

The following satisfaction level was tapped on the current walkways and the surrounding environment.

Table 6: Satisfaction level of pedestrian towards the current walkway environment

\begin{tabular}{lcc}
\hline I am satisfied with the overall current & & \\
walkway environment. & Frequency & Percentage \\
\hline Strongly disagree & 28 & 7.5 \\
Disagree & 77 & 20.0 \\
Somewhat disagree & 142 & 36.9 \\
Agree & 94 & 24.4 \\
Strongly agree & 43 & 11.2 \\
Total & 384 & 100.0 \\
\hline
\end{tabular}

Table 6 indicates the results of the satisfaction level of the walkways environment. Most of the pedestrians choose somewhat disagree with this question which consists of $36.9 \%$. And the second most chosen scale which is agreed has $94(24.4 \%)$ respondents. There are on 29 respondents $(7.5 \%)$ who reported a strongly disagree in this statement. 
Table 7: Satisfaction level of pedestrian towards the cleanliness of current pedestrian walkways

\begin{tabular}{lcc}
\hline I feel satisfied with the overall cleanliness of the & & \\
existing pedestrian walkways. & Frequency & Percentage \\
\hline Strongly disagree & 33 & 8.8 \\
Disagree & 152 & 39.5 \\
Neutral & 67 & 17.4 \\
Somewhat disagree & 68 & 17.7 \\
Strongly agree & 64 & 16.6 \\
Total & 384 & 100.0 \\
\hline
\end{tabular}

Based on Table 7, the majority of the respondent had indicated that they disagree (152 respondents out of 384) with the current cleanliness surrounding pedestrian walkways. Only $16.6 \%$ of the total respondents are satisfied with the ongoing cleanliness of the present pedestrian's sidewalks. Despite that, the current accessibility level has also tapped The result is depicted in the following Table 8.

Table 8: Satisfaction on current accessibility of the walkways

\begin{tabular}{ccc}
\hline I am satisfied with the overall existing pedestrian & & \\
walkway's accessibility & Frequency & Percentage \\
\hline Strongly disagree & 14 & 3.6 \\
Disagree & 166 & 43.1 \\
Somewhat disagree & 721 & 18.7 \\
Agree & 101 & 26.2 \\
Strongly agree & 31 & 8.3 \\
Total & 384 & 100.0 \\
\hline
\end{tabular}

From the table above, most of the pedestrians had indicated that they disagree with the statement of current pedestrian accessibility, which consists of $43.1 \%$. Only $26.2 \%$ of the respondent had reported their agreement on the availability of existing pedestrian walkways.

\subsection{Discussion}

From the descriptive analysis of the result, the study highlight that majority of the pedestrian still indicate high dissatisfaction towards the current provision of the pedestrian walkways especially in terms of cleanliness, comfortability, accessibility and walkways environment. Thus if more people were to encourage walking in future, these are the most crucial aspect to be considered in every town planning.

Looking at the descriptive analysis on the demographic side, most of the pedestrian is among the captive users who do not always have a choice to travel to their destinations (workplace in the city centre) using other modes of transport. Thus, there is a massive possibility of people switching mode given the choice of a private car. Therefore, understanding their needs through their satisfaction is crucial in ensuring that walking will be a continuous mode in future regardless of their income level improvement or availability of the private car. 


\subsection{Conclusion}

The present study of pedestrian satisfaction towards pedestrian walkways had identified several factors that significantly affect their appreciation of the current pedestrian walkways. This includes walkway comfortability, cleanliness, accessibility and connectivity when all the variables stand on their own. All of these factors are being investigated to have a remarkable impact and affected the overall satisfaction level. Several strategies need to be done to increase the satisfaction level of the current pedestrian users which include a wellmaintained schedule to clean rubbish surrounding, a proper trees plantation as to create more comfortability walking experience, and last, but not least the improvement should also be targeted on the high connectivity and accessibility.

\section{Acknowledgement}

A special thanks to all parties involved directly and indirectly with the completion of this paper. A heartfelt thanks go to UCSI University under the Faculty of Business for all the resources given during the completion process of this paper.

\section{References}

Alam, S.B., \&Tasneem, S. (2018). Improving Sustainable Pedestrian Facilities in Congested Urban Areas Adapting Breeam Assessment: A Case of Dhaka, Bangladesh. Asian Journal of Applied Science and Engineering, 7(1), 720.

Asadi-Shekar, Z., Moeinaddini, M. \& Shah, M.Z.(2015). "Pedestrian Safety Index for Evaluating Street Facilities in Urban Areas". Safety Science, 74,1-14.

Ariffin, R. N. R., \&Zahari, R. K. (2013). Perceptions of the urban walking environments. Procedia-Social and Behavioral Sciences, 105, 589-597.

Borst, H. C., Vries, S.I.D, Graham, J.M.A., Dongen, J.E.F., Bakker, I., Miedema, H.M.E. (2009). Influence of environmental street characteristics on walking route choice of elderly people. Journal of Environmental Psychology, 29(4), 477-484

Maslow, A.H. (1954). Motivation and Personality. Harper and Row, New York.

Mateo-Babiano, I. (2016). Pedestrian's needs matters: Examining Manila's walking environment. Transport Policy, 45, 107-115

Nakatsukasa, M. \& Suzuki, A. (2017). Evaluation of Comfortability in walking on street space with physiological indices. Journal of the Eastern Asia Society for Transportation Studies, 12, 1176-1191.

Obeng-Atuah, D., Poku-Boansi, M., \&Cobbinah, P. B. (2017). Pedestrian crossing in urban Ghana: Safety implications. Journal of Transport \& Health, 5, 55-69

Shafabakhsh, G., Mirzanamadi, R., \&Mohammadi, M. (2015). Pedestrians' mental satisfaction's relationship with physical characteristics on sidewalks using analytical hierarchy process: a case study of Tehran, Iran. Transportation Letters, 7(3), 121-132. 
Rankavat, S., \& Tiwari, G. (2016). Pedestrians perceptions for utilization of pedestrian facilities - Delhi, India. Transportation Research Part F: Traffic Psychology and Behaviour, 42, 495-499

Rupasinghe, H.T., Wickramasinghe, L.M.M.N. \&R.U.Halwatura. (2018). Street greenery; a vital planning integration to overcome carbon dioxide concentration and pedestrian discomfort in urban streetscapes. Engaging Architectural Science: Meeting the Challenges of Higher Density: 52nd International Conference of the Architectural Science Association 2018, 545-552.

Sham, R., Omar, N. \&Amat, D.W. (2013). Women and crime in the central business district area. Journal Of Asian Behavioural Studies, 3(11), 123-134.

Tjahjono, T., Farizi, A. S. A. \&Intan, D.P. (2017). Determining an Acceptability of Pedestrian Facilities to Support the Mass Transport System in Jakarta. Journal of Technology and Social Science (JTSS), 1(3), 33-40.

World Health Organization. (2013). Violence, injury prevention, \& World Health Organization. Global status report on road safety 2013: supporting a decade of action. World Health Organization.

Zakaria, J. \&Ujang, N. (2015). The Comfort of Walking in The City Center of Kuala Lumpur. Asian Conference on Environment-Behaviour Studies.AcE-Bs Seoul, Korea Procedia - Social and Behavioral Sciences, 170, 642-652. 